Progress in Oceanography

March 2017, Volume 152, Pages 1-14

http://dx.doi.org/10.1016/i.pocean.2016.12.010

http://archimer.ifremer.fr/doc/00371/48207/

(C) 2017 Elsevier Ltd. All rights reserved.

\title{
Environmentally driven synchronies of Mediterranean cephalopod populations
}

\author{
Keller Stefanie ${ }^{1,{ }^{*}}$, Quetglas Antoni ${ }^{1}$, Puerta Patricia ${ }^{1}$, Bitetto Isabella ${ }^{2}$, Casciaro Loredana ${ }^{2}$, \\ Cuccu Danila ${ }^{3}$, Esteban Antonio ${ }^{4}$, Garcia Cristina ${ }^{5}$, Garofalo Germana ${ }^{6}$, Guijarro Beatriz ${ }^{1}$, \\ Josephide Marios $^{7}$, Jadaud Angelique ${ }^{8}$, Lefkaditou Evgenia ${ }^{9}$, Maiorano Porzia ${ }^{10}$, Manfredi Chiara ${ }^{11}$, \\ Marceta Bojan ${ }^{12}$, Micallef Reno ${ }^{13}$, Peristeraki Panagiota ${ }^{14,17}$, Relini Giulio ${ }^{15}$, Sartor Paolo ${ }^{16}$, \\ Teresa Spedicato Maria ${ }^{2}$, Tserpes George ${ }^{14}$, Hidalgo Manuel ${ }^{1}$
}

${ }^{1}$ Instituto Español de Oceanografía (IEO), Centro Oceanográfico de Baleares, Muelle de Poniente, s/n, Apdo. 291, 07015 Palma de Mallorca, Spain

${ }^{2}$ COISPA-Tecnologia \& Ricerca, Stazione Sperimentale per lo Studio delle Risorse del Mare, Bari, Italy

${ }^{3}$ Dipartemento di Scienze della Vita e dell'Ambiente, Università di Cagliari, Cagliari, Italy

${ }^{4}$ IEO, Centro Oceanográfico de Murcia, San Pedro del Pinatar, Murcia, Spain

${ }^{5}$ IEO, Centro Oceanográfico de Malaga, Fuengirola, Málaga, Spain

${ }_{7}^{6}$ IAMC - Coastal Marine Environment Insitute - CNR, Mazara del Vallo (TP), Italy

${ }^{7}$ DFMR - Department of Fisheries and Marine Research, Ministry of Agriculture, Rural Development and Environment, Nicosia, Cyprus

${ }^{8}$ Ifremer, Institut Français de Recherche pour l'Exploitation de la mer, UMR 212 Ecosystèmes Marins Exploités (EME), Sète, France

${ }^{9}$ HCMR, Hellenic Centre of Marine Research, Athens, Greece

${ }_{11}^{10}$ University of Bari Aldo Moro - Department of Biology, Bari, Italy

${ }^{11}$ Laboratorio Biologia Marina e Pesca, Università di Bologna, Fano (PS), Italy

${ }^{12}$ Fishery Research Institute of Slovenia, Ljubljana-Smartno, Slovenia

${ }^{13}$ Ministry for Sustainable Development, Department of Fisheries and Aquaculture, Marsa, Malta

${ }^{14}$ HCMR, Hellenic Centre of Marine Research, Heraklion, Crete, Greece

${ }^{15}$ SIBM, Società Italiana di Biologia Marina, Genova and DISTAV, Università di Genova, Genova, Italy

${ }^{16} \mathrm{CIBM}$ - Centro Interuniversitario di Biologia Marina ed Ecologia Applicata, Livorno, Italy

${ }^{17}$ University of Crete, Biology Department, Heraklion, Crete, Greece

*Corresponding author : Stefanie Keller, email address : stefanie.keller@ba.ieo.es

\begin{abstract}
:
The Mediterranean Sea is characterized by large scale gradients of temperature, productivity and salinity, in addition to pronounced mesoscale differences. Such a heterogeneous system is expected to shape the population dynamics of marine species. On the other hand, prevailing environmental and climatic conditions at whole basin scale may force spatially distant populations to fluctuate in synchrony. Cephalopods are excellent case studies to test these hypotheses owing to their high sensitivity to environmental conditions. Data of two cephalopod species with contrasting life histories (benthic octopus vs nectobenthic squid), obtained from scientific surveys carried out throughout the Mediterranean during the last 20 years were analyzed. The objectives of this study and the methods used to achieve them (in parentheses) were: i) to investigate synchronies in spatially separated
\end{abstract}


populations (decorrelation analysis); ii) detect underlying common abundance trends over distant regions (dynamic factor analysis, DFA); and iii) analyse putative influences of key environmental drivers such as productivity and sea surface temperature on the population dynamics at regional scale (general linear models, GLM). In accordance with their contrasting spatial mobility, the distance from where synchrony could no longer be detected (decorrelation scale) was higher in squid than in octopus (349 vs $217 \mathrm{~km}$ ); for comparison, the maximum distance between locations was $2620 \mathrm{~km}$. The DFA revealed a general increasing trend in the abundance of both species in most areas, which agrees with the already reported worldwide proliferation of cephalopods. DFA results also showed that population dynamics are more similar in the eastern than in the western Mediterranean basin. According to the GLM models, cephalopod populations were negatively affected by productivity, which would be explained by an increase of competition and predation by fishes. While warmer years coincided with declining octopus numbers, areas of high sea surface temperature showed higher densities of squid. Our results are relevant for regional fisheries management and demonstrate that the regionalisation objectives envisaged under the new Common Fishery Policy may not be adequate for Mediterranean cephalopod stocks.

\section{Highlights}

- Synchronies in population dynamics of Mediterranean cephalopod species are revealed. A general increasing trend in cephalopod abundances is found. Temperature and productivity affect population dynamics on a regional scale. Populations are more closely connected in the Eastern than in the Western basin. Results are relevant for current European management regulations.

Keywords: Cephalopods, Mediterranean, MEDITS, Dynamic factor analysis, synchrony, Octopus vulgaris, Illex coindetii

\section{Introduction}

The Mediterranean Sea is generally shaped by large scale gradients of temperature, productivity and salinity (D'Ortenzio and d'Alcalá, 2009). However, it is also known as a complex ecosystem with contrasting regions in terms of productivity (Nieblas et al., 2014), seafloor topography and hydrography (Millot, 2005; Rossi et al., 2014). In an ecosystem with 
such pronounced regional differences, animal populations are prone to exhibit patchy distributions due to different habitat conditions. Such patchiness has been observed analysing feeding habitats of high trophic level species such as whales and tuna (Druon et al., 2011, 2012, 2016), the distribution of secondary consumers such as cephalopods or small elasmobranchs (Puerta et al., 2015, 2016a; Navarro et al., 2016) or nursery grounds and spawning areas of commercially important species (Druon et al., 2011, 2015; Colloca et al., 2015). All these studies revealed that hydrographic conditions (Druon et al., 2011, 2015), bathymetric features like depth and type of seafloor (Druon et al., 2012; Colloca et al., 2015) and productivity (Druon et al., 2011, 2012; Puerta et al., 2016a) are key drivers of distribution patterns.

Environmental and large-scale climatic variability may force spatially distant populations to fluctuate in synchrony (Liebhold et al., 2004). Comparing the dynamics of spatially distant populations allows detecting the main drivers of abundance fluctuations and the scale at which they operate (Descamps et al., 2013), and thus the degree of connectivity of neighbouring populations. In synchronized populations, drastic declines in population size likely affect all populations simultaneously, exposing them to a greater risk of extinction (Descamps et al., 2013 and references therein). By contrast, heterogeneous and complex populations generally show higher resilience and recovery rates and are more likely to withstand mass elimination (Schindler et al., 2010). Therefore, knowledge about the underlying mechanisms of population dynamics at large spatial scales has important implications for the management and conservation of species (Liebhold et al., 2004).

Large-scale synchronic fluctuations have been described in phytoplankton (Doyle and Poore, 1974), zooplankton (Batchelder et al., 2012), fish (Kelly et al., 2009) and crustaceans (Koeller et al., 2009; Hidalgo et al., 2015). However, very little is known about cephalopods. This group is considered excellent for case studies to analyze synchronic fluctuations, owing to its sensitivity to changing environmental conditions as a result of its fast growth rates and short life cycles (Pierce et al., 2008). Among the environmental parameters investigated until 
now, sea surface temperature (SST) plays an important role in driving cephalopod abundance trends (Zuur and Pierce, 2004; Chen, 2010). Additionally, a recent study investigated local scale seasonal synchronies in Mediterranean cephalopod abundances (Puerta et al., 2016b), revealing contrasting seasonal cycles in response to local environmental conditions.

Due to the decline in the traditional finfish resources, European cephalopod fisheries, which were once located mostly in the Mediterranean, have grown and expanded northwards (Pierce et al., 2010). This expansion is expected to continue as a result of the increasing market demand of cephalopods, whereby regular assessments and certain management measures would be needed to ensure a sustainable exploitation. Under the current Common Fisheries Policy (CFP; EU Regulation № 1380/2013), the regionalization approach may lead to a revision of the management areas currently in place in the Mediterranean (see below). For a successful implementation, gaining knowledge of the mechanisms controlling stock fluctuations is essential, as defining management areas merging independently fluctuating populations may result in strong miss-management. Sound scientific knowledge is necessary to implement management areas appropriately matching the biological distribution of populations as demanded by the new CFP in their regionalised ecosystem-based approach.

Here we analyse the population dynamics of two commercially important cephalopods (Sartor et al., 1998; Quetglas et al., 2000) with contrasting life histories, the nectobenthic broadtailed shortfin squid Illex coindetii and the benthic common octopus Octopus vulgaris, in the whole Mediterranean Sea. The data analysed were obtained from scientific surveys carried out throughout the Mediterranean during the last 20 years. The objectives of this study are three-fold. For each species, we first analyse the global correlation structure across the entire Mediterranean Sea to assess how the similarity in population abundances of spatially separated populations (or population sub-units) decreases with distance. Second, we use dynamic factor analysis to detect underlying common abundance trends over distant regions. Finally, we analyse putative influences of key environmental 
drivers (productivity and SST) on the population dynamics at regional scale using general linear models.

\section{Material and Methods}

\subsection{DATA SOURCE}

Data were obtained from the international Mediterranean bottom trawl survey MEDITS (http://www.sibm.it/SIT0\%20MEDITS/), which is conducted every year in spring / early summer (May-August) since 1994, covering depths from $10 \mathrm{~m}$ down to $800 \mathrm{~m}$. The surveys are performed by all riparian EU countries, in addition to Montenegro and Albania, and are the most comprehensive data sources to investigate demersal ecosystems in the entire Mediterranean. The sampling methodology is standardized among all the countries (for details see Bertrand et al., 2002 and A.A.V.V., 2016). A stratified random sampling design is used for this survey, with bathymetric strata comprising 10-50, 51-100, 101-200, 201-500 and 501-800 m. The standardized gear used is a GOC 73 trawl with a cod-end mesh size of 20 $\mathrm{mm}$ and a vertical and horizontal opening of the net of about $2 \mathrm{~m}$ and $18 \mathrm{~m}$ respectively (Bertrand et al., 2002). The net opening is measured by an attached underwater Scanmar or SIMRAD system, which allows calculating the swept area. Trawling is conducted during daylight, with a towing speed of about 3 knots and haul duration of 30 and 60 minutes over shelf and slope grounds respectively. Haul catches are sorted to species level whenever possible. Abundance data for each species are standardized to number of individuals per $\mathrm{km}^{2}$ using the mean stratified swept area method (Saville, 1977; Souplet, 1996). Mean abundances per GSA were then obtained taking into account only the strata where $95 \%$ of the catches occurred, and including all valid hauls of these strata.

The geographical sub-areas (GSA's; Fig 1) established by the General Fisheries Commission for the Mediterranean (http://www.fao.org/gfcm/en/) for assessment and management have been used as spatial units in the present study. Some areas sampled only in recent and/or very few years were excluded from these analyses (GSA 2, 15 and 25). 
Although Greece did not conduct the surveys in 2007 and 2009-2012, its data were included as they represent the easternmost data points of the time series. The final dataset included 15 GSAs and comprised between 13 and 20 years depending on GSA. In total, 20463 hauls were analysed.

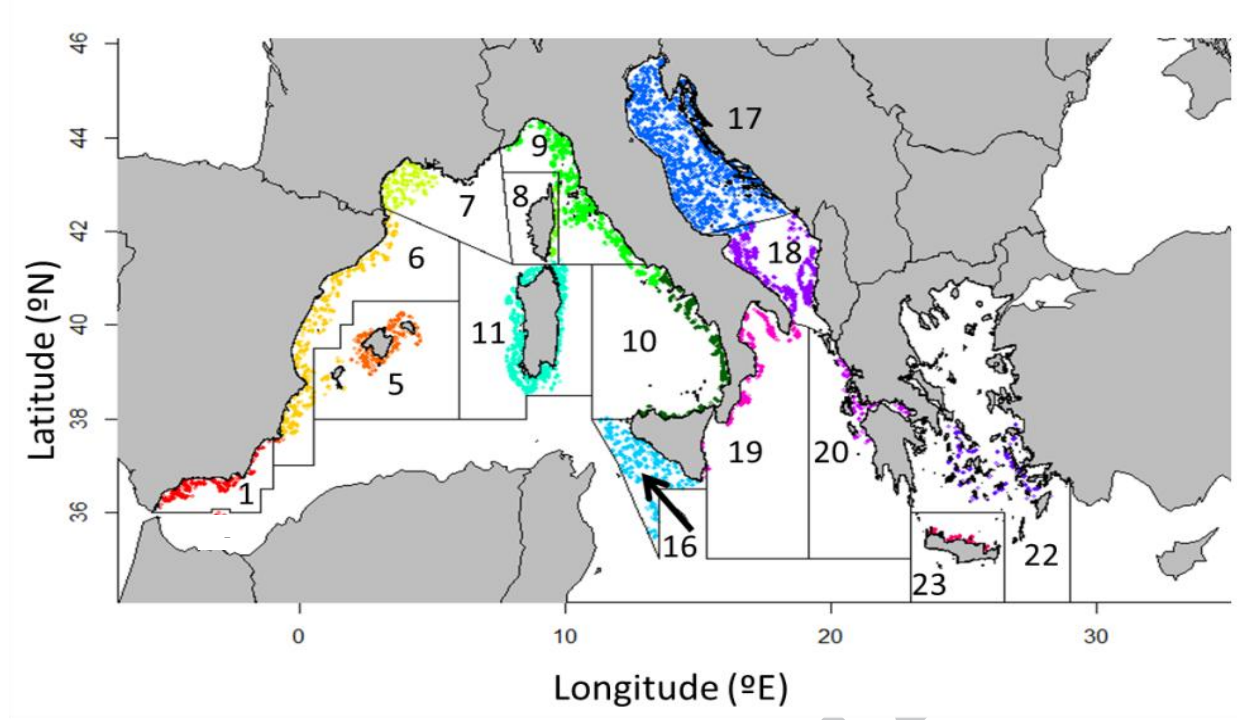

- GSA 1 - Northern Alboran - GSA 5 - Balearic Islands GSA 6 - Northern Spain GSA 7 - Gulf of Lions GSA 8 - Corsica GSA 9 - Ligurian + North TS - GSA 10 - South + Central TS - GSA 11 - Sardinia GSA 16 - South of Sicily - GSA 17 - Northern Adriatic

- GSA 18 - Southern Adriatic

- GSA 19 - Western Ionian

- GSA 20 - Eastern Ionian

- GSA 22 - Aegean

- GSA 23 - Crete

Figure 1: Map of the Mediterranean Sea showing the geographical sub-areas (GSAs) established by the General Fisheries Commission for the Mediterranean (GFCM) and the MEDITS stations sampled during 1994-2013.

\subsection{DATA ANALYSIS}

\subsubsection{Decorrelation analysis}

For both study species (Octopus vulgaris and Illex coindetii), the Pearson's correlation coefficient $r$ was calculated for each pair of abundance time series and plotted against the distance between the GSAs' centres of gravity (Woillez et al., 2007). A centre of gravity is the mean location of an individual taken at random in the field, and discrete summation over sampling locations divided by population density gives the average location of a population in the respective sampling area. This method only takes into consideration positive records, that is sampling locations where cephalopods have been found (Woillez et al., 2007). To correct for differences in time series lengths, each coefficient was weighted by the length of the corresponding time series. The graphical output (spatial correlogram) shows the decline of synchrony with distance (Kelly et al., 2009) and the spatial scale of synchrony. The distance 
from where synchrony can no longer be detected is referred to as "decorrelation scale". Points were fitted by non-linear least squares estimation using an exponential fit:

$$
q_{d}=q_{0} e^{-d / v}
$$

with $q_{d}$ being the Pearson's $r$ correlation coefficient between CPUE time series of a pair of locations, $q_{0}$ the estimated correlation between CPUEs at zero distance, $d$ stands for the distance between locations $(\mathrm{km})$, and $1 / \mathrm{v}\left(\mathrm{km}^{-1} ; \mathrm{v}>0\right)$ is the decay rate that estimates spatial correlation scale as the e-folding scale of the exponential fit, i.e., the distance at which $q_{d}=e^{-1}$ (Kelly et al., 2009).

\subsubsection{Dynamic Factor Analysis (DFA)}

To identify underlying common trends in abundance among time series, a Dynamic Factor Analysis (DFA, Zuur et al., 2003) was used. This technique can cope with nonstationary data, short time series and also missing values (Zuur et al., 2003), and has already been implemented for the identification of temporal trends of exploited species in various studies (Zuur et al., 2003; Erzini, 2005; Chen et al., 2008; Chen and Lee, 2013). DFA is a dimension reduction technique in which a set of time series are modelled as a linear combination of underlying common trends + factor loadings (+ covariates) + error terms to explain temporal variability. Factor loadings indicate how much each time series resembles each common trend. Covariates can be included, but only one yearly value per model. As this is not appropriate in a heterogeneous and extensive environment like the Mediterranean Sea, the effect of covariates will be unmasked separately by means of General Linear Models (see below). The correlation of observation errors can be modelled using different error matrices: i) same variance and no covariance (diagonal-equal); ii) different variances and no covariance (diagonal-unequal); iii) same variance and covariance (equalvarcov); and iv) different variances and covariances (unconstrained). For both species, the correlations of 
observation errors were fitted to all possible model structures in the time series, including 1 up to 3 common trends.

Owing to pronounced differences in environmental conditions (temperature, productivity regimes), oceanographic properties and hydrography between the western and eastern Mediterranean basins (Lascaratos et al., 1999), two separate DFA-analyses were conducted grouping GSAs according to their location. GSAs 1-16 are positioned in the western Mediterranean, while GSAs 17-23 are located in the eastern basin. In this analysis, we included time series of 13-20 years length from 15 different GSAs. For comparison, abundance data were scaled between 0 and 1.

The Akaike information criterion (AIC) was used as a measure of goodness-of-fit, the best model having the lowest AIC (Zuur et al., 2003; Chen and Lee, 2013). All analyses were done in R (version 3.2.1; http://www.r-project.org/) using the Multivariate Autoregressive State-Space (MARSS) package (Holmes et al., 2012).

\subsubsection{General Linear Models}

General Linear Models (GLM) were applied to investigate the influence of environmental drivers on the abundance of the two objective species. Sea surface temperature (SST) and chlorophyll $a$ concentration (Chla) were used as putative drivers owing to their significant effects on cephalopod populations (Keller et al., 2014; Pierce et al., 2008b; Puerta et al., 2016b). Chla and SST data resulted from MODIS-Aqua and NPP-VIIRS sensors measurements already processed with regional ocean colour algorithms (resolution $1 \mathrm{~km}$, daily data) and were downloaded from the MyOcean database (http://marine.copernicus.eu/web/69-interactive-catalogue.php). The availability of satellite data restricted this analysis to the time series of 1998-2012 from 15 GSA's. Available survey years per GSA reach from a minimum of 9 to a maximum of 15 years.

Cephalopod abundances (response variable) were modelled using the following explanatory variables: SST, Chla, year and GSA. Year and GSA were considered factors. Mean 
seasonal Chla and SST were averaged separately for each GSA for all years. Chla concentration was used as a proxy for food availability and was modelled using seasonal means of: i) the spring (March-May) before the survey, and ii) the preceding winter (December-February). By doing that we account for different time lags (time required for energy transfer between trophic levels), and also for the fact that food availability will influence ecological and metabolic processes differently across ontogeny. For this last reason, the same two seasons were used to calculate mean seasonal SST. Covariates (Chla, SST) and seasons (winter, spring) of year were chosen as they proofed to be good descriptors of the key oceanographic processes determining spring productivity in the Mediterranean (Lloret et al., 2001; Quetglas et al., 2011).

Two different models, designed for different purposes, were constructed for each species. The first one (non-standardized model) included the log of the catch per unit effort (CPUE) as response variable and attempts to detect proportional (temporal and spatial) effects between CPUE and environmental covariates:

Log (CPUE) YEAR + GSA + Chla_Winter + Chla_Spring + SST_Winter + SST_Spring.

The second model (standardized model) was based on standardized data for CPUE, SST and Chla (data scaled between 0 and 1). This model is specifically designed to look at the influence of the covariates on the inter-annual variability once spatial gradients are removed, taking into account the interactions between SST/Chla and the GSAs to analyse regionalspecific differences of environmental influences. This model therefore detects possible drivers for synchronic behaviour of spatially distant populations:

CPUE (standardized) $\sim$ YEAR + GSA + Chla_Winter + Chla_Spring + SST_Winter + SST_Spring + Chla_Winter:GSA + Chla_Spring:GSA + SST_Winter:GSA + SST_Spring:GSA. 
As spring and winter variables of Chl /SST were correlated, models with both spring and winter values of the same covariate were excluded. All GLM analyses were carried out with R (version 3.2.1, packages $m g c v$ and $M u M l n$ ) assuming Gaussian error distribution and using the identity link function. Models were selected according to their sample-size corrected Akaike Information Criterion (AICc), with the model resulting in the lowest value being considered the best fit (Burnham and Anderson, 2004). The variance inflation factor (VIF) was calculated for the best model to confirm the absence of correlation amongst covariates (VIF < 5). Model residuals were checked for variance homogeneity and normal distribution.

\section{Results}

\subsection{Abundance data}

CPUEs of Octopus vulgaris normally do not exceed 300 individuals $/ \mathrm{km}^{2}$, with the exceptions of the Alboran and the Balearic Sea, where the highest catches occurred (Fig $2 \mathrm{a}+$ b). Except in the Northern Adriatic and western Ionian Sea (GSA 17, 19), CPUEs show an often remarkable - increase in the year 2011. Octopus catches were generally higher in the western basin. The opposite is true for the Illex coindetii abundances, which are generally lower in the west (Fig $2 \mathrm{c}+\mathrm{d}$ ). Squid CPUEs were highest in the waters around Crete (GSA 23), while lowest in the Gulf of Lions (GSA 7) and around the Balearic Islands and Corsica (GSA 5, 8), although the last two areas showed high abundances in some recent years. The high squid abundance in Northern Spain in 2000 was based on various high catches and is no outlier. 


\section{Eastern basin}

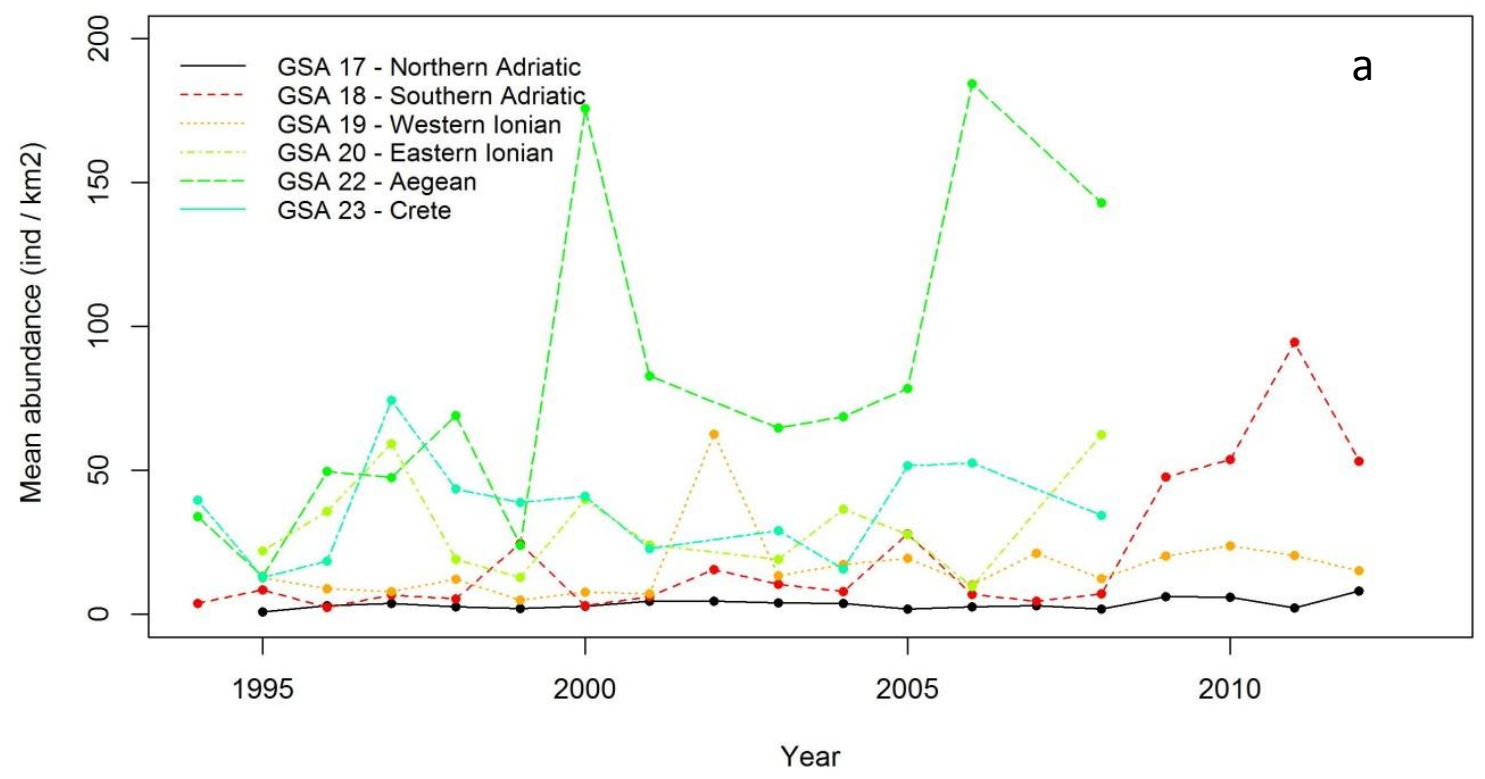

Western basin

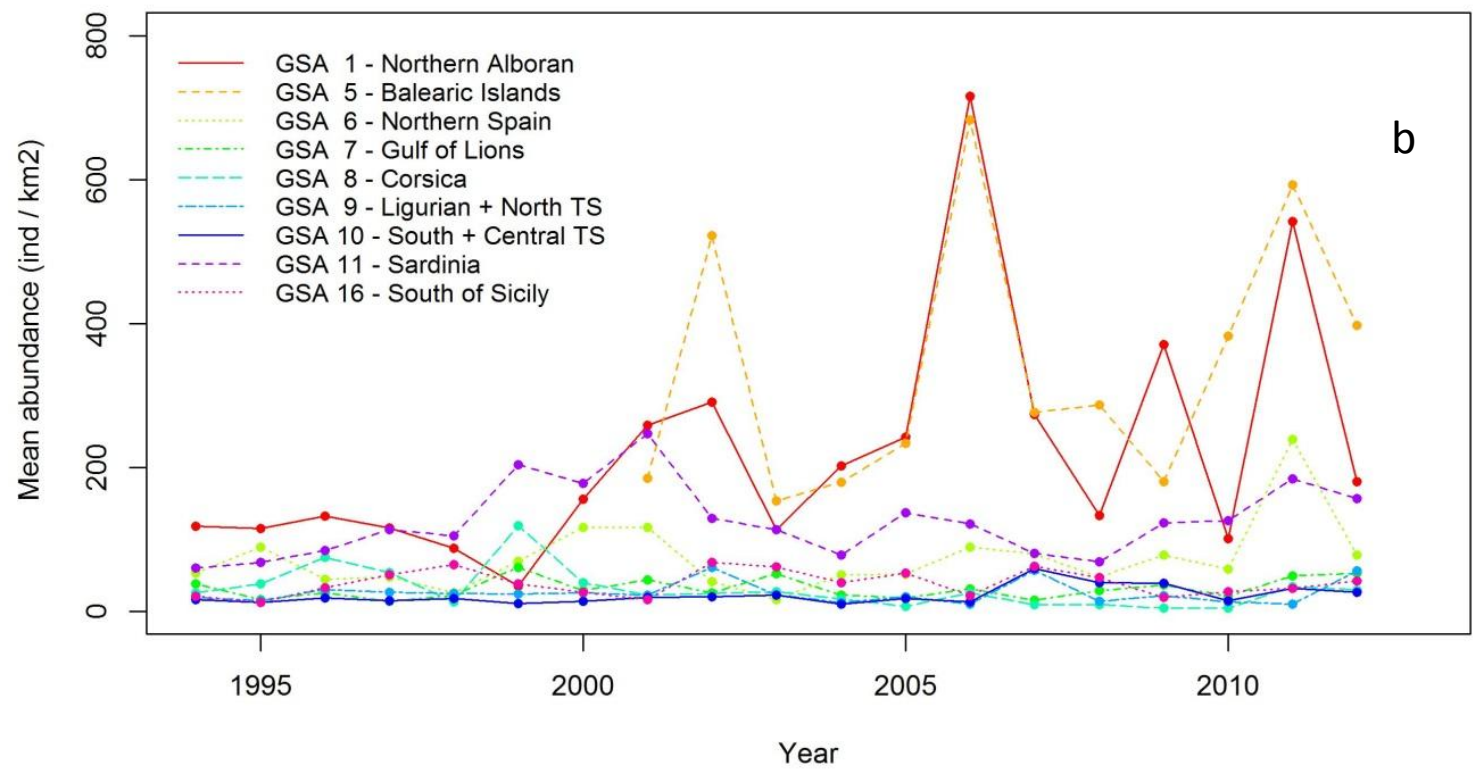




\section{Eastern basin}

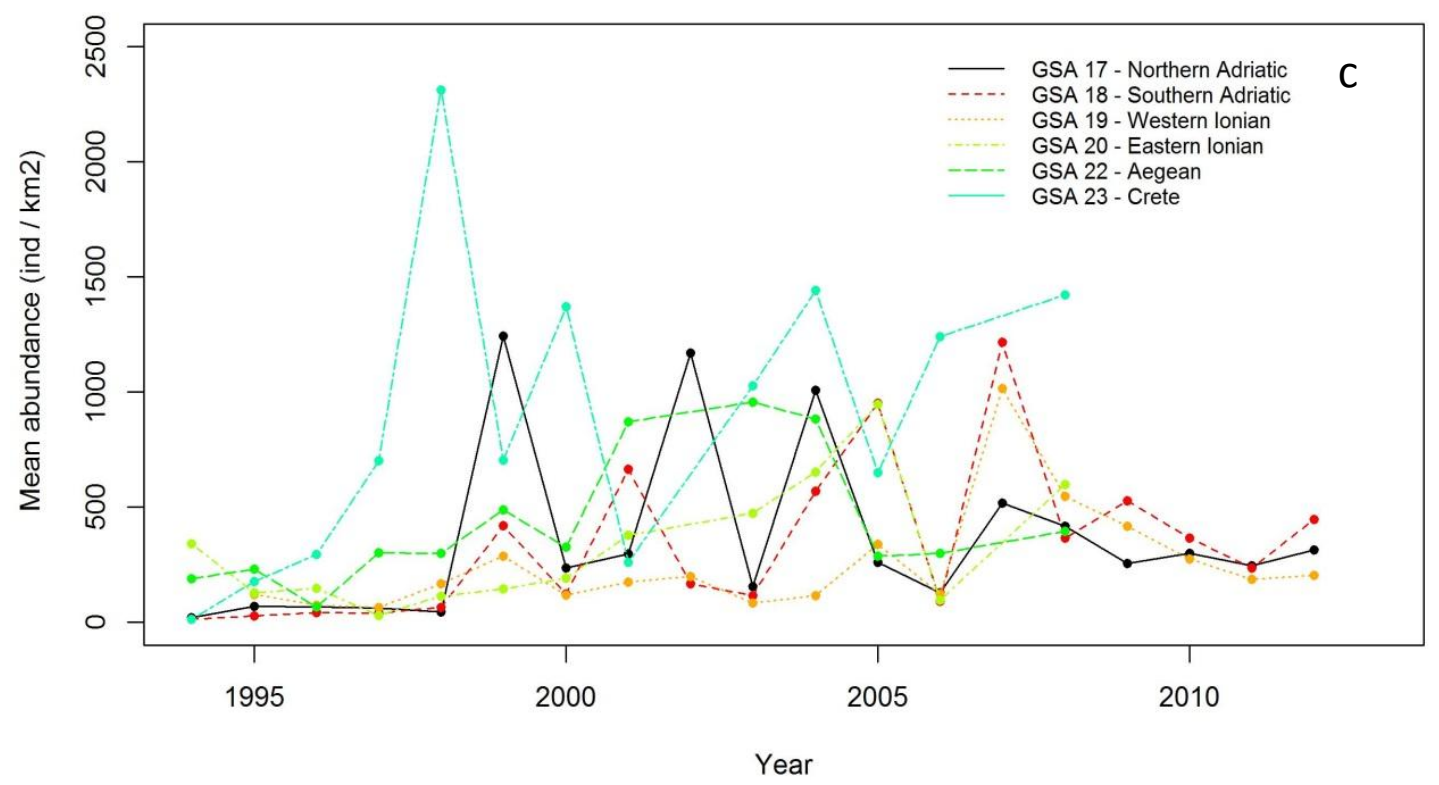

Western basin

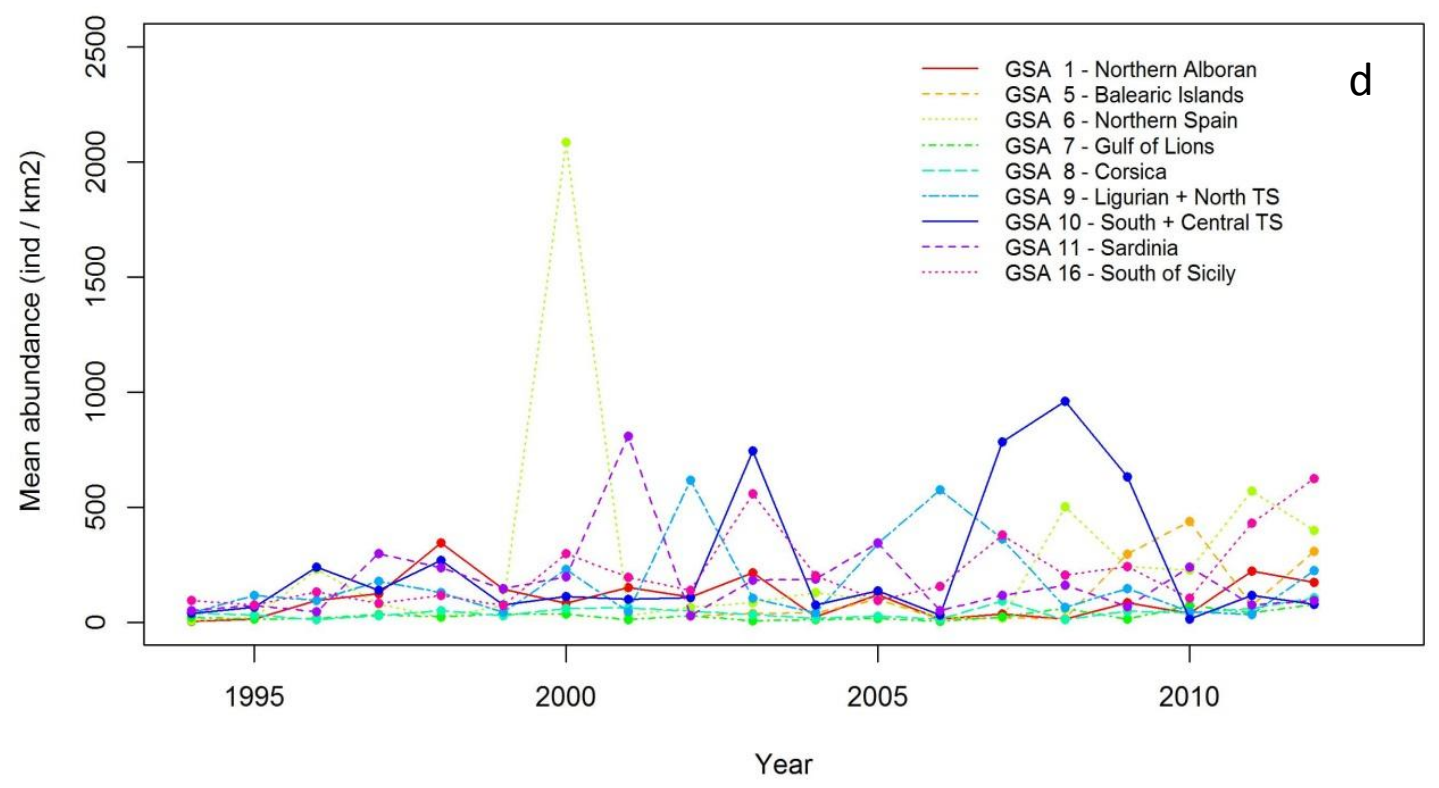

Figure 2: Time series of CPUEs (ind $\cdot \mathrm{km}^{-2}$ ) for Octopus vulgaris (a, b) and Illex coindetii (c, d) in the eastern and western Mediterranean basin from 1994 to 2012. TS = Tyrrhenian Sea. 


\subsection{Decorrelation analysis}

As expected, correlations between locations decreased with distance, describing a significant non-linear fit $(\mathrm{p}<0.05)$ for both species (Fig 3). The decorrelation scale was higher for squid $(349 \pm 43 \mathrm{~km})$ than for octopus $(217 \pm 37 \mathrm{~km})$. For comparison, the maximum distance between locations was around $2620 \mathrm{~km}$.
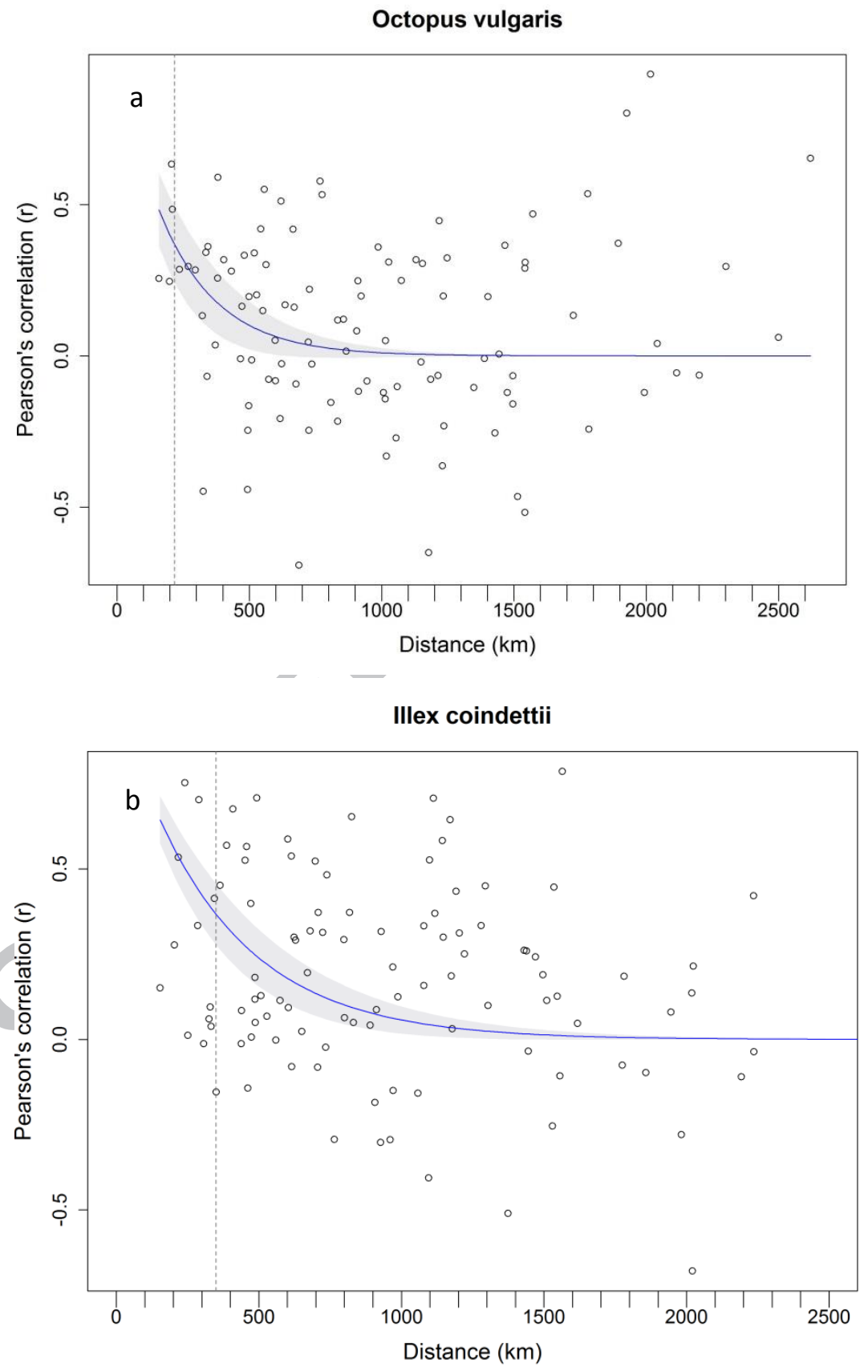

Figure 3: Correlograms of CPUEs of Octopus vulgaris (a) and Illex coindetii (b) showing the Pearson's correlation coefficients between all pairs of time series versus their distances. Model fits (least-square estimates, blue lines) and confidence intervals (in grey) are shown. Vertical lines indicate the spatial decorrelation scale. 


\subsection{Dynamic Factor Analysis}

For both species and in both basins, the best DFA model had a single common trend and observation errors either with equal variances and no covariance (diagonal and equal) or equal variances and covariances (equalvarcov) (Table A1). All trends exhibit higher values in 2012 than at the start of the time series in 1994 (Fig 4). Furthermore, all trends show an increase in CPUEs during the last few years.

The common abundance trends for octopus show a steady rise in the eastern basin and a slightly time-delayed rise in the western basin, with abundances increasing continuously only from 1999 onwards. The factor loadings reveal that octopus abundances follow the common rising trend in all areas except the waters around Crete (GSA 23, Fig 4 b) in the eastern basin and around Corsica and south of Sicily (GSAs 8 and 16, Fig 4 d) in the western basin.

Although squid abundances showed a general increasing trend with time on both basins (Fig $4 \mathrm{e}+\mathrm{g}$ ), the western one was truncated with a small decrease during 2000-2006 (Fig 4 g). In the eastern basin, factor loadings of all areas were positive with no opposite trends (Fig $4 \mathrm{f}$ ). Factor loadings for the western basin show that the Tyrrhenian and the Ligurian Sea (GSAs 9 and 10) and the waters of Sardinia (GSA 11) follow abundance trends opposite to the common trend (Fig $4 \mathrm{~h}$ ). 

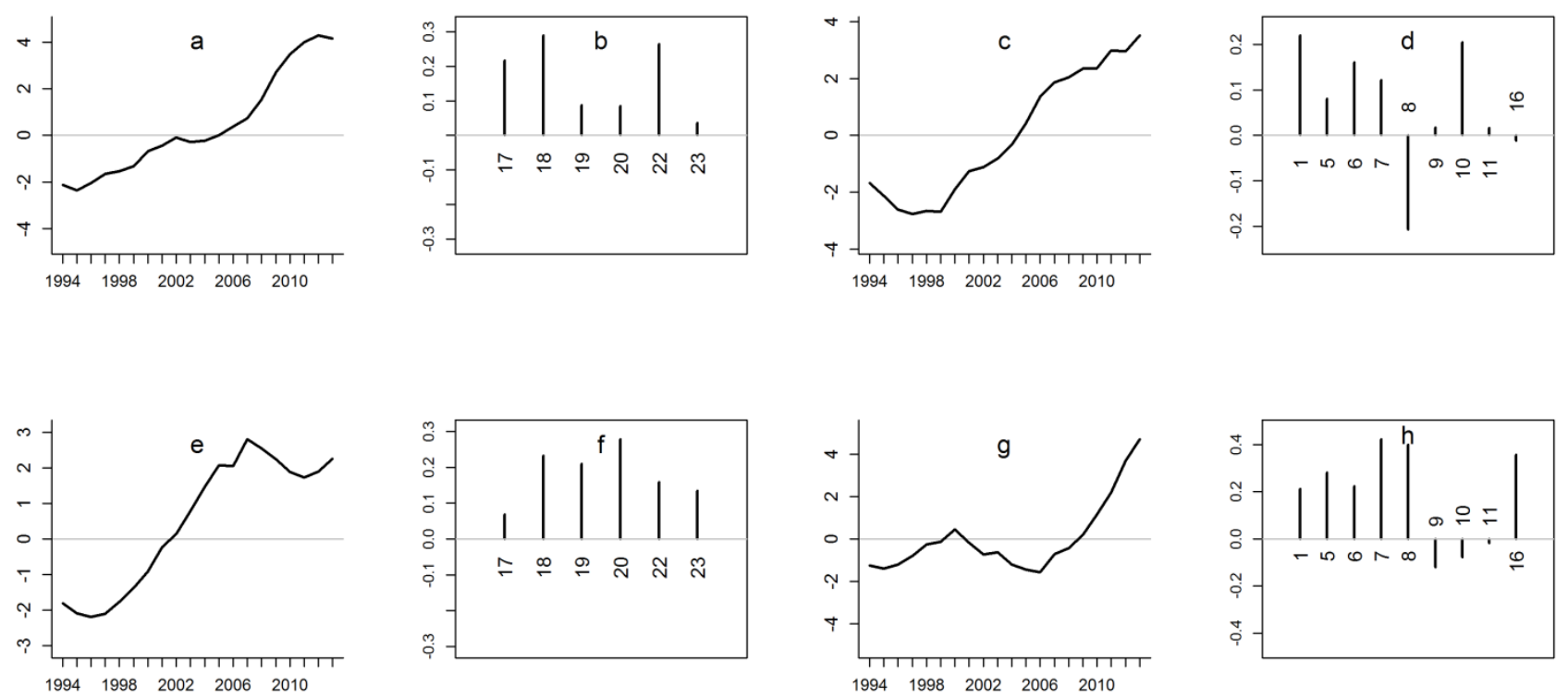

Figure 4: Common trends and factor loadings resulting from the Dynamic Factor Analysis of CPUE time series of Octopus vulgaris (above) and Illex coindetii (below) in the eastern (left) and western (right) basin during 1994-2013. GSAs are denoted by their numbers and located as seen in Figure 1. All y-axis are unitless.

\subsection{General Linear Models}

The best model predicting the non-standardized CPUEs of octopus was obtained including the factor GSA only (Table 2). In the standardized model, both Chla content of the spring concurrent with the surveys and the SST of the previous winter were retained in the best model (Fig $5 \mathrm{a}+\mathrm{b}$ ). Both parameters negatively affected the inter-annual octopus abundances, independently of the region. 
Table 1: Results of both non-standardized and standardized Generalized Linear Models for Octopus vulgaris and Illex coindetii. The five best models for each case are shown (best model in bold; significant variables marked by an asterisk for $p<0.05$ and by + for $p<0.1)$. For each model, the covariates, the degrees of freedom (df), and the corrected Akaike Information Criterion (AICC) are given. Covariates: Year of sampling (factor, year), GSA (factor, gsa_f), mean chlorophyll a concentration in spring or winter

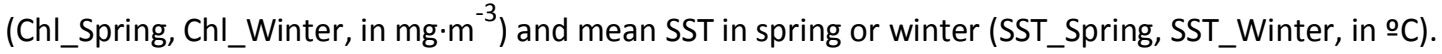

\begin{tabular}{|c|c|c|c|c|c|}
\hline $\begin{array}{l}\text { Octopus non- } \\
\text { standardized model }\end{array}$ & $\mathrm{df}$ & AICc & Octopus standardized model & df & $\mathrm{AICC}$ \\
\hline gsa_f & 16 & 389.09 & ChI_Spring $^{*}+$ SST_Winter ${ }^{+}$ & 4 & 72.20 \\
\hline gsa_f +Chl_Spring & 17 & 390.20 & Chl_Spring & 3 & 73.96 \\
\hline gsa_f + Chl_Spring + SST_Winter & 18 & 391.27 & SSTSpring & 3 & 75.35 \\
\hline gsa_f + year_f & 30 & 396.32 & Chl_Spring + SST_Spring & 4 & 75.65 \\
\hline gsa_f + year_f +SST_Spring & 31 & 396.46 & Chl_Winter & 3 & 76.21 \\
\hline
\end{tabular}

\begin{tabular}{|l|r|l|l|r|r|}
\hline Illex non-standardized model & df & AlCc & Illex standardized model & df & AICc \\
\hline gsa_f + SSTSpring* + Chl_Winter & 18 & 541.86 & SST_Winter & & \\
\hline gsa_f + Chl_Winter & 17 & 542.70 & Chl_Winter + SST_Spring & 3 & 64.54 \\
\hline gsa_f & 16 & 544.15 & Chl_Winter + SST_Winter & 4 & 65.00 \\
\hline gsa_f + SST_Winter +Chl_Winter & 18 & 544.33 & SST_Spring & 3 & 65.32 \\
\hline gsa_f + year_f + Chl_Winter & 31 & 547.00 & Chl_Winter & 3 & 65.87 \\
\hline
\end{tabular}

The best fit for squid in the non-standardized model was obtained including the GSA as factor, the Chla content of the preceding winter and the SST during spring (Table 2). The coloured residuals evidenced that the negative effect of Chla on CPUEs was due to a geographic gradient in productivity (Fig 6 a). The SST had a slightly positive effect on squid CPUEs that was also due to the thermal geographic gradient in the Mediterranean (Fig $6 \mathrm{~b}$ ). The model of standardized CPUEs revealed that the SST of the preceding winter positively affects inter-annual squid abundances, independently of the mean CPUE per area (Fig 6 c). 
In general, both the standardized and non-standardized models gave consistent results

(Table 2). While Chla correlated negatively with CPUEs, the correlation between CPUEs and SST varied with species and was negative for octopus, but positive for squid. The factor GSA improved the un-standardized models only, while the factor year resulted to be nonsignificant.
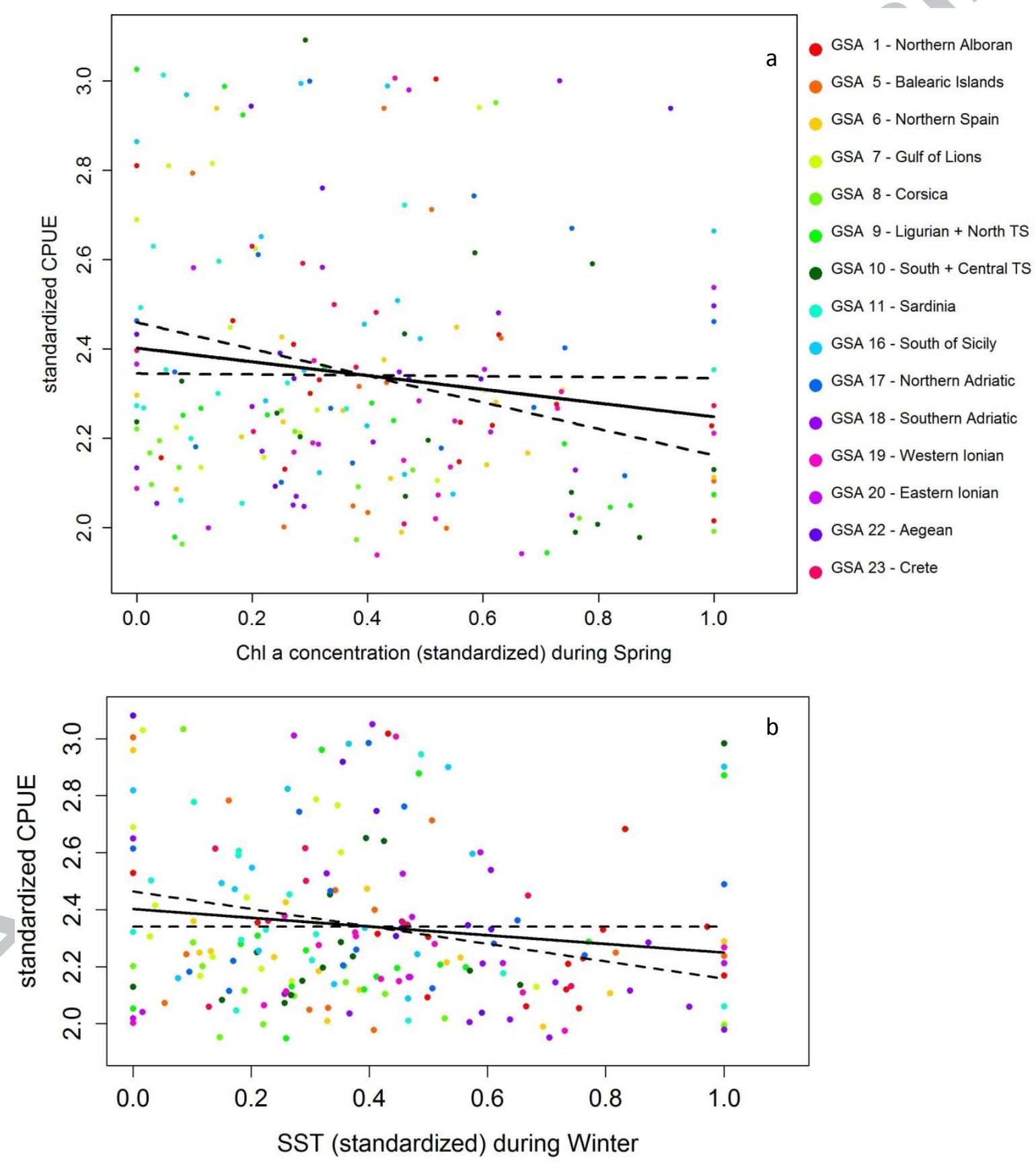

Figure 5: Model predictions and confidence intervals (dashed lines) of the effect of Chla content (a) and SST (b) on Octopus vulgaris CPUEs (GLM results of the standardized best model). Partial residuals colours are coded by GSA. TS = Tyrrhenian Sea. 

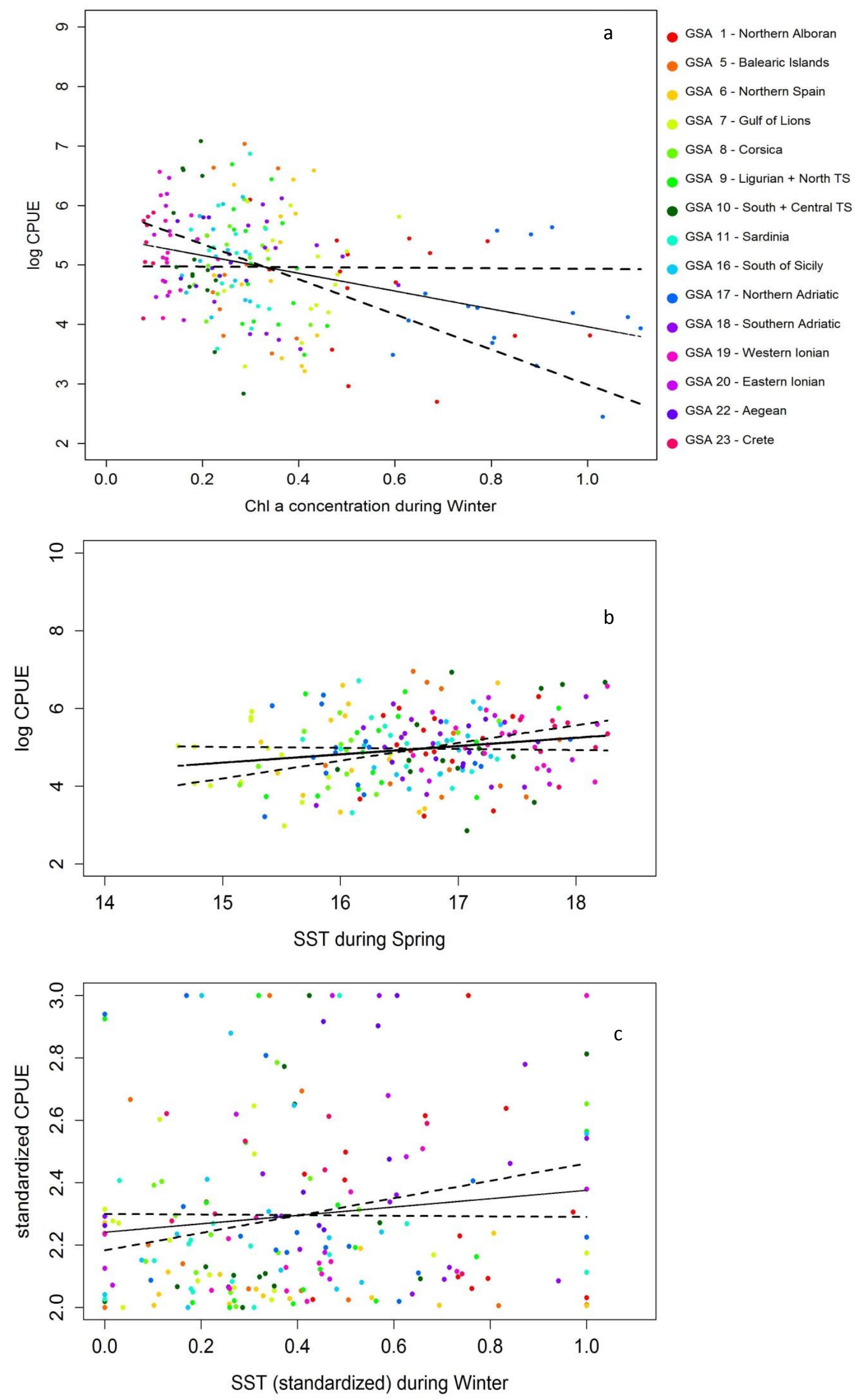
Figure 6: Model predictions and confidence intervals (dashed lines) of the effect of Chla content and SST on Illex coindetii CPUEs (GLM results): unstandardized $(\mathrm{a}+\mathrm{b})$ and standardized best model (c). Partial residuals colours are coded by GSA. TS = Tyrrhenian Sea.

\section{Discussion}

The strength and nature of the synchrony among populations affects the abundances, resilience and recovery of connected populations, with important implications for their management. In this study, large-scale population dynamics of two cephalopod species with contrasting life histories were analyzed combining three different methods. In the decorrelation analysis, higher correlation coefficients mean higher connectivity and therefore higher synchrony between locations. Similar dynamics have been revealed within smaller distances for octopus (Octopus vulgaris) than for squid (Illex coindetii). Our results are in accordance with a previous work at smaller spatial scale, where the correlation scale of $I$. coindetii was bigger than that of $O$. vulgaris both around the Balearic Islands and off the Mediterranean coast of the Iberian Peninsula (Puerta et al., 2016b). Results are likely related to the fact that $I$. coindetii is an oceanic species with higher mobility and a wider home range (Roper et al., 2010). This characteristic should lead to closer connections even between more distant populations of the squid. This neritic species also lives in deeper waters in the Mediterranean (Roper et al., 2010) and, therefore, most likely experiences a more homogeneous environment than the shallow-water octopus. Although it could be speculated that due to the squid's higher mobility, there are only 1-2 population in the Mediterranean, results of a recent research project reveal that, most likely, there are 4-8 separate stock units throughout this sea (Fiorentino et al., 2014). In contrast, for O. vulgaris, 3 (sub-)populations are considered most probable according to the project's report (Fiorentino et al., 2014).

The DFA results revealed that populations of both species followed the modelled common trends in all (eastern basin) or most (western basin) study areas. Synchronic population fluctuations can be due to different mechanisms such as (Liebhold et al., 2004; Gouhier et al., 2010): i) predator-prey interaction; ii) dispersal of individuals between populations; or iii) large-scale climatic events or environmental influences affecting various 
populations in the same way. The first one is very improbable due to the nature of cephalopods as rather unselective and adaptable predators (Rodhouse and Nigmatullin, 1996; Coll et al., 2013) and the different interannual prey dynamics in such a heterogeneous system as the Mediterranean. Connectivity via dispersal should lead to more similar abundance time series in neighbouring areas, but our results of the decorrelation analysis do not support a direct linkage over many hundreds of kilometres either. Therefore, the observed abundance fluctuations are more likely due to large-scale climatic phenomena or synchronous environmental influences.

Supporting the last hypothesis, our results revealed a negative influence of chlorophyll $a$ content (Chla) on the abundances of both cephalopod species, a result that has already been reported on a smaller scale in the Western Mediterranean for I. coindetii (Puerta et al., 2015). Those authors argue that small pelagic fishes, which make up an important part of the Mediterranean food chain (Coll et al., 2006), are effective competitors for food with early and juvenile stages of squid species like I. coindetii. Higher Chla contents will usually foster the survival and growth of small fish, enhancing food competition and, thus, reduce cephalopod survival and abundance. The mechanism does not seem to differ among different areas, as interactions between $\mathrm{Chl}$ / SST and GSA were not significant. The GSA was only statistically significant in the non-standardized models, accounting for abundance variability among areas.

Apart from productivity, rising temperatures would cause declining abundances in octopus (standardized model), but warmer areas do not necessarily have fewer octopus, as other factors apparently play a more crucial role in determining their abundances and distribution. The mechanism for the negative temperature effect could be a stronger and more durable stratification of water masses during summer, causing less nutrient mixing and therefore lower phytoplankton and zooplankton growth rates. Warmer temperatures indeed induced a reduction of zooplankton abundance together with a change in community composition and structure in the study area (Fernández de Puelles et al., 2008), which might 
negatively affect zooplankton consumers. The common octopus preys directly on zooplankton during its paralarval stage (Roura et al., 2010) but it is also indirectly linked to zooplankton abundance via the food web, as it mainly consumes small mollusks and crustaceans (Quetglas et al., 1998; Roura et al., 2010). For squid, the temperature effect is different, as warmer areas show higher abundances (non-standardized model) and SST positively influences inter-annual abundance changes (standardized model). Warmer ecosystems support higher metabolic rates, higher food intake and growth (Segawa and Nomoto, 2002; Semmens et al., 2004) and can therefore foster higher squid abundances.

Our study reveals, for the first time, increasing trends in population abundance of two cephalopod species throughout the entire Mediterranean over the last 20 years, which is in accordance with the worldwide global trend reported recently (Doubleday et al., 2016). While the GLM results show the importance of Chla and SST on the abundance of both species, the similar trends in all the 15 survey areas of very different temperature and productivity regimes suggests that additional forces, acting at regional scale, are at play. The rising abundances are likely to be due to the constant, high fishing effort in this sea over decades (Colloca et al., 2013; Vasilakopoulos et al., 2014), reducing (directly or indirectly) the abundance of key cephalopod competitors and predators like bony fish, sharks and whales. Various studies have already observed changes in food webs, where the missing predators have been replaced by lower-level species (Pauly et al., 1998; Myers and Worm, 2003; Frank et al., 2005). While depletion of their predators releases the predation pressure on cephalopods (Caddy and Rodhouse, 1998), (over)fishing of species with similar habitat and resource needs will release competition pressure and open new ecological niches. Cephalopods are fast-growing, opportunistic and adaptable species with short generation times. They are generalist predators, which enables them to take advantage of changing trophic relations and rapid colonisation of new habitats (Jackson and O'Dor, 2001; Rodhouse et al., 2014). Therefore, ecosystem changes due to fishing exploitation could explain some of the observed rising catches of cephalopod species around the world (Caddy and Rodhouse, 1998; Vecchione et al., 2009), even though opinions differ on the importance and implication 
of other factors such as changed fishing tactics, new techniques and gears, license issues and environmental influences (Balguerías, 2000). While the direct impact of the commercial fishery on stocks is evident, amount and composition of bycatch may play an indirect role by supplying additional food to scavengers like crustaceans, an important prey of octopus species (Oro et al., 2013). Crustaceans often survived being discarded, and the commercial fishery may therefore indirectly cause an increase in octopus abundances in two different ways (Balguerías, 2000).

Climate change, or the synchronic effects of climate and harvesting, might also explain the proliferation of cephalopods (Doubleday et al., 2016). Apart from the discussed effect of rising temperatures, it causes further ecosystem changes (e.g. acidification, distribution shifts, altered productivity regimes, enhanced stratification) which may lead to competitive advantages for this taxon (Hoving et al., 2013). However, on a physiological and morphological basis, the effects of climate change will likely be negative at least at the early life stage, leading to a complex response of still uncertain direction (Pecl and Jackson, 2008). In terms of primary production, the two Mediterranean basins are likely to be affected by climate change in different ways (Macias et al., 2015): while the eastern basin will probably experience an increase in Chla due to vertical density changes caused by a combination of warming and salinization, the western basin is expected to have decreasing Chla concentrations. According to our results this would lead to increasing cephalopod abundances in this basin, while their abundance would decrease in the eastern basin. However, it is still a matter of further research whether other influences and ecosystem changes will mask and buffer this effect.

On smaller spatial scales, additional oceanographic features can cause synchronic population dynamics. Specific local conditions may explain the rather stable squid abundance (Fig A1) in the Tyrrhenian and Ligurian waters (including all waters around Sardinia), where eddies might retain paralarvae, causing a separate population dynamic in these waters. In the Ligurian Sea, this mechanism of retention has already been proposed to be of relevance for 
hake larvae (Abella et al., 2008). Furthermore, these waters are characterised by resident Atlantic waters, which are more saline than Spanish and French coastal and off-shore waters (Reglero et al., 2012). Other local scale processes leading to separate population dynamics are river run-offs, which have been suggested to foster the abundances of certain cephalopod species including O. vulgaris and I. coindetii (Lloret et al., 2001; Puerta et al., 2014, 2016b).

Up to now, all available studies investigating the influence of environmental and climatic effects on cephalopod populations from the Mediterranean Sea were carried out at local scales (Lloret et al., 2001; Quetglas et al., 2013; Keller et al., 2014; Puerta et al., 2014, 2016b). However, analysis at broader spatial scales are needed, especially in the framework of the regionalisation process envisaged under the new CFP (Article 18 of the EU Regulation № 1380/2013). In this sense, our study, which encompassed the whole Mediterranean basin, constitutes an important step forward with clear relevance for fisheries management in the area. Our results and those from previous works seem to be at odds with the regionalisation objectives. Cephalopods from the western basin, even those of high mobility rates like squids, displayed complex population structures and dynamics at local scales (Puerta et al., 2014) and were correlated only within a radius of a few hundred kilometres (Puerta et al., 2016b; this work). Nevertheless, the situation may differ between basins because populations from the eastern basin were more strongly connected than those from the western basin. In spite of the population complexities, our work also revealed common trends of rising abundances during the last 20 years, which agree with the global proliferation of cephalopods (Doubleday et al., 2016). 


\section{References}

A.A.V.V., 2016. MEDITS-Handbook. Version n. 8. MEDITS Working Group 177 pp. doi:(http://www.sibm.it/MEDITS\%202011/principalemedits.htm)

Abella, A., Fiorentino, F., Mannini, A., Orsi Relini, L., 2008. Exploring relationships between recruitment of European hake (Merluccius merluccius L. 1758) and environmental factors in the Ligurian Sea and the Strait of Sicily (Central Mediterranean). Journal of Marine Systems 71, 279-293. doi:10.1016/j.jmarsys.2007.05.010

Balguerías, E., 2000. The origin of the Saharan Bank cephalopod fishery. ICES Journal of Marine Science 57, 15-23. doi:10.1006/jmsc.1999.0572

Batchelder, H.P., Mackas, D.L., O’Brien, T.D., 2012. Spatial-temporal scales of synchrony in marine zooplankton biomass and abundance patterns: A world-wide comparison. Progress in Oceanography 97-100, 15-30. doi:10.1016/j.pocean.2011.11.010

Bertrand, J.A., Gil de Sola, L., Papaconstantinou, C., Relini, G., Souplet, A., 2002. The general specifications of the MEDITS surveys. Scientia Marina 66, 9-17.

Burnham, K.P., Anderson, D.R., 2004. Multimodel Inference: Understanding AIC and BIC in Model Selection. Sociological Methods \& Research 33, 261-304.

Caddy, J.F., Rodhouse, P.G., 1998. Cephalopod and groundfish landings: evidence for ecological change in global fisheries? Review in Fish Biology and Fisheries 8, 431444.

Chen, C., 2010. Abundance trends of two neon flying squid (Ommastrephes bartramii) stocks in the North Pacific. ICES Journal of Marine Science 1336-1345.

Chen, C.-S., Lee, B.-W., 2013. Trends in trawl-targeted species landings off northern Taiwan and effects of fishing and environmental factors. Fisheries Science 79, $163-$ 176. doi:10.1007/s12562-013-0601-1

Chen, X., Chen, Y., Tian, S., Liu, B., Qian, W., 2008. An assessment of the west winterspring cohort of neon flying squid (Ommastrephes bartramii) in the Northwest Pacific Ocean. Fisheries Research 92, 221-230. doi:10.1016/j.fishres.2008.01.011

Coll, M., Navarro, J., Olson, R.J., Christensen, V., 2013. Assessing the trophic position and ecological role of squids in marine ecosystems by means of food-web models. Deep Sea Research Part II: Topical Studies in Oceanography 95, 21-36. doi:10.1016/j.dsr2.2012.08.020

Coll, M., Palomera, I., Tudela, S., Sardà, F., 2006. Trophic flows, ecosystem structure and fishing impacts in the South Catalan Sea, Northwestern Mediterranean. Journal of Marine Systems 59, 63-96. doi:10.1016/j.jmarsys.2005.09.001

Colloca, F., Cardinale, M., Maynou, F., Giannoulaki, M., Scarcella, G., Jenko, K., Bellido, J.M., Fiorentino, F., 2013. Rebuilding Mediterranean fisheries: a new paradigm for ecological sustainability. Fish and Fisheries 14, 89-109. doi:10.1111/j.14672979.2011.00453.x

Colloca, F., Garofalo, G., Bitetto, I., Facchini, M.T., Grati, F., Martiradonna, A., Mastrantonio, G., Nikolioudakis, N., Ordinas, F., Scarcella, G., Tserpes, G., Tugores, M.P., Valavanis, V., Carlucci, R., Fiorentino, F., Follesa, M.C., Iglesias, M., Knittweis, L., Lefkaditou, E., Lembo, G., Manfredi, C., Massutí, E., Pace, M.L., Papadopoulou, N., Sartor, P., Smith, C.J., Spedicato, M.T., 2015. The seascape of demersal fish nursery areas in the North Mediterranean Sea, a first step towards the implementation of spatial planning for trawl fisheries. PloS One 10, e0119590. 
doi:10.1371/journal.pone.0119590

D’Ortenzio, F., Ribera d'Alcalà, M., 2009. On the trophic regimes of the Mediterranean Sea : a satellite analysis. Biogeosciences 6, 139-148.

Descamps, S., Strøm, H., Steen, H., 2013. Decline of an arctic top predator: synchrony in colony size fluctuations, risk of extinction and the subpolar gyre. Oecologia 173, 1271-1282. doi:10.1007/s00442-013-2701-0

Doubleday, Z.A., Thomas, A.A., Arkhipkin, A., Pierce, G.J., Semmens, J., Steer, M., Leporati, S.C., Lourenço, S., Quetglas, A., Sauer, W., Bronwyn, M., 2016. Global proliferation of cephalopods. Current Biology Magazine 26, 1-3.

Doyle, R.W., Poore, R. V., 1974. Nutrient competition and division synchrony in phytoplankton. Journal of Experimental Marine Biology and Ecology 14, 201-210.

Druon, J.-N., Fiorentino, F., Murenu, M., Knittweis, L., Colloca, F., Osio, C., Mérigot, B., Garofalo, G., Mannini, A., Jadaud, A., Sbrana, M., Scarcella, G., Tserpes, G., Peristeraki, P., Carlucci, R., Heikkonen, J., 2015. Modelling of European hake nurseries in the Mediterranean Sea: An ecological niche approach. Progress in Oceanography 130, 188-204. doi:10.1016/j.pocean.2014.11.005

Druon, J.-N., Fromentin, J.-M., Hanke, A.R., Arrizabalaga, H., Damalas, D., Tičina, V., Quílez-Badia, G., Ramirez, K., Arregui, I., Tserpes, G., Reglero, P., Deflorio, M., Oray, I., Saadet Karakulak, F., Megalofonou, P., Ceyhan, T., Grubišić, L., MacKenzie, B.R., Lamkin, J., Afonso, P., Addis, P., 2016. Habitat suitability of the Atlantic bluefin tuna by size class: An ecological niche approach. Progress in Oceanography 142, 30-46. doi:10.1016/j.pocean.2016.01.002

Druon, J., Fromentin, J., Aulanier, F., Heikkonen, J., 2011. Potential feeding and spawning habitats of Atlantic bluefin tuna in the Mediterranean Sea. Marine Ecology Progress Series 439, 223-240. doi:10.3354/meps09321

Druon, J., Panigada, S., David, L., Gannier, A., Mayol, P., Arcangeli, A., Cañadas, A., Laran, S., Di Méglio, N., Gauffier, P., 2012. Potential feeding habitat of fin whales in the western Mediterranean Sea: an environmental niche model. Marine Ecology Progress Series 464, 289-306. doi:10.3354/meps09810

Erzini, K., 2005. Trends in NE Atlantic landings (southern Portugal): identifying the relative importance of fisheries and environmental variables. Fisheries Oceanography $14,195-209$.

Fernández de Puelles, M.L., Lopéz-Urrutia, Á., Morillas, A., Molinero, J.C., 2008. Seasonal variability of copepod abundance in the Balearic region (Western Mediterranean) as an indicator of basin scale hydrological changes. Hydrobiologia 617, 3-16. doi:10.1007/s10750-008-9522-x

Fiorentino, F., Massutì, E., Tinti, F., Somarakis, S., Garofalo, G., Russo, T., Facchini, M.T., Carbonara, P., Kapiris, K., Tugores, P., Cannas, R., Tsigenopoulos, C., Patti, B., Colloca, F., Sbrana, M., Mifsud, R., Valavanis, V., Spedicato, M.T., 2014. STOCKMED: "Stock units: Identification of distinct biological units (stock units) for different fish and shellfish species and among different GFCM-GSA."

Frank, K.T., Petrie, B., Choi, J.S., Leggett, W.C., 2005. Trophic cascades in a formerly cod-dominated ecosystem. Science 308, 1621-3. doi:10.1126/science.1113075

Gouhier, T.C., Guichard, F., Menge, B. a, 2010. Ecological processes can synchronize marine population dynamics over continental scales. Proceedings of the National Academy of Sciences of the United States of America 107, 8281-6. doi:10.1073/pnas.0914588107 
Hidalgo, M., Rueda, L., Molinero, J.C., Guijarro, B., Massutí, E., 2015. Spatial and temporal variation of seasonal synchrony in the deep-sea shrimp Aristeus antennatus in the Western Mediterranean. Journal of Marine Systems 148, 131-141. doi:10.1016/j.jmarsys.2015.02.007

Holmes, E.E., Ward, E.J., Wills, K., 2012. MARSS : Multivariate Autoregressive Statespace Models for Analyzing Time-series Data. The R Journal 4, 11-19.

Hoving, H.-J.T., Gilly, W.F., Markaida, U., Benoit-Bird, K.J., -Brown, Z.W., Daniel, P., Field, J.C., Parassenti, L., Liu, B., Campos, B., 2013. Extreme plasticity in life-history strategy allows a migratory predator (jumbo squid) to cope with a changing climate. Global change biology 19, 2089-103. doi:10.1111/gcb.12198

Jackson, G.D., O'Dor, R.K., 2001. Time, space and the ecophysiology of squid growth, life in the fast lane. Vie et Milieu 51, 205-215.

Keller, S., Valls, M., Hidalgo, M., Quetglas, A., 2014. Influence of environmental parameters on the life-history and population dynamics of cuttlefish Sepia officinalis in the western Mediterranean. Estuarine, Coastal and Shelf Science 145, 31-40. doi:10.1016/j.ecss.2014.04.016

Kelly, J., Frank, K., Leggett, W., 2009. Degraded recruitment synchrony in Northwest Atlantic cod stocks. Marine Ecology Progress Series 393, 131-146. doi:10.3354/meps08241

Koeller, P., Fuentes-Yaco, C., Platt, T., Sathyendranath, S., Richards, a, Ouellet, P., Orr, D., Skúladóttir, U., Wieland, K., Savard, L., Aschan, M., 2009. Basin-scale coherence in phenology of shrimps and phytoplankton in the North Atlantic Ocean. Science (New York, N.Y.) 324, 791-3. doi:10.1126/science.1170987

Lascaratos, A., Roether, W., Nittis, K., Klein, B., 1999. Recent changes in deep water formation and spreading in the eastern Mediterranean Sea : a review. Progress in Oceanography 44, 5-36.

Liebhold, A., Koenig, W.D., Bjørnstad, O.N., 2004. Spatial Synchrony in Population Dynamics. Annual Review of Ecology, Evolution, and Systematics 35, 467-490. doi:10.1146/annurev.ecolsys.34.011802.132516

Lloret, J., Lleonart, J., Sole, I., Fromentin, J.M., 2001. Fluctuations of landings and environmental conditions in the north-western Mediterranean Sea. Fisheries Oceanography 10, 33-50. doi:10.1046/j.1365-2419.2001.00151.x

Macias, D.M., Garcia-Gorriz, E., Stips, A., 2015. Productivity changes in the Mediterranean Sea for the twenty-first century in response to changes in the regional atmospheric forcing. Frontiers in Marine Science 2, 1-13. doi:10.3389/fmars.2015.00079

Millot, C., 2005. Circulation in the Mediterranean Sea : evidences, debates and unanswered questions. Scientia Marina 69, 5-21.

Myers, R.A., Worm, B., 2003. Rapid worldwide depletion of predatory fish communities. Letters to Nature 423, 280-283.

Navarro, J., Cardador, L., Fernández, Á.M., Bellido, J.M., Coll, M., 2016. Differences in the relative roles of environment, prey availability and human activity in the spatial distribution of two marine mesopredators living in highly exploited ecosystems. Journal of Biogeography 43, 440-450. doi:10.1111/jbi.12648

Nieblas, A.-E., Drushka, K., Reygondeau, G., Rossi, V., Demarcq, H., Dubroca, L., Bonhommeau, S., 2014. Defining Mediterranean and Black Sea biogeochemical subprovinces and synthetic ocean indicators using mesoscale oceanographic features. 
PloS One 9, 1-13. doi:10.1371/journal.pone.0111251

Oro, D., Genovart, M., Tavecchia, G., Fowler, M.S., Martínez-Abraín, A., 2013.

Ecological and evolutionary implications of food subsidies from humans. Ecology Letters 16, 1501-14. doi:10.1111/ele.12187

Pauly, D., Christensen, V., Dalsgaard, J., Froese, R., Torres, F.J., 1998. Fishing Down Marine Food Webs. Science 279, 860-863.

Pecl, G.T., Jackson, G.D., 2008. The potential impacts of climate change on inshore squid: biology, ecology and fisheries. Reviews in Fish Biology and Fisheries 18, 373-385.

Pierce, G.J., Allcock, L., Bruno, I., Jereb, P., Lefkaditou, E., Malham, S., Moreno, A., Pereira, J., Piatkowski, U., Rasero, M., Sánchez, P., Santos, M.B., Santurtún, M., Seixas, S., Sobrino, I., Villanueva, R., 2010. Cephalopod biology and fisheries in Europe. ICES Cooperative Research Report 303, 175.

Pierce, G.J., Valavanis, V.D., Guerra, A., Jereb, P., Orsi-Relini, L., Bellido, J.M., Katara, I., Piatkowski, U., Pereira, J., Balguerias, E., Sobrino, I., Lefkaditou, E., Wang, J., Santurtun, M., Boyle, P.R., Hastie, L.C., MacLeod, C.D., Smith, J.M., Viana, M., González, A.F., Zuur, A.F., 2008. A review of cephalopod-environment interactions in European Seas. Hydrobiologia 612, 49-70. doi:10.1007/s10750-008-9489-7

Puerta, P., Hidalgo, M., González, M., Esteban, A., Quetglas, A., 2014. Role of hydroclimatic and demographic processes on the spatio-temporal distribution of cephalopods in the western Mediterranean. Marine Ecology Progress Series 514, 105118. doi:10.3354/meps10972

Puerta, P., Hunsicker, M.E., Hidalgo, M., Reglero, P., Ciannelli, L., Quetglas, A., Esteban, A., 2016a. Community-environment interactions explain octopus-catshark spatial overlap. ICES Journal of Marine Science 73, 1901-1911. doi:doi:10.1093/icesjms/fsw053

Puerta, P., Hunsicker, M.E., Quetglas, A., Álvarez-Berastegui, D., Esteban, A., González, M., Hidalgo, M., 2015. Spatially Explicit Modeling Reveals Cephalopod Distributions Match Contrasting Trophic Pathways in the Western Mediterranean Sea. PloS One 10, e0133439. doi:10.1371/journal.pone.0133439

Puerta, P., Quetglas, A., Hidalgo, M., 2016b. Seasonal variability of cephalopod populations: a spatio-temporal approach in the Western Mediterranean Sea. Fisheries Oceanography 25, 373-389.

Quetglas, A., Alemany, F., Carbonell, A., Merella, P., Sanchez, P., 1998. Biology and fishery of Octopus vulgaris Cuvier, 1797, caught by trawlers in Mallorca (Balearic Sea, Western Mediterranean). Fisheries Research 36, 237-249.

Quetglas, A., Carbonell, A., Sanchez, P., 2000. Demersal continental shelf and upper slope cephalopod assemblages from the balearic sea (north-western Mediterranean).

Biological aspects of some deep-sea species. Estuarine Coastal and Shelf Science 50, 739-749.

Quetglas, A., Ordines, F., Hidalgo, M., Monserrat, S., Ruiz, S., Amores, A., Moranta, J., Massuti, E., 2013. Synchronous combined effects of fishing and climate within a demersal community. ICES Journal of Marine Science 70, 319-328.

Quetglas, A., Ordines, F., Valls, M., 2011. What drives seasonal fluctuations of body condition in a semelparous income breeder octopus? Acta Oecologica 37, 476-483. doi:10.1016/j.actao.2011.06.002

Reglero, P., Ciannelli, L., Alvarez-Berastegui, D., Balbín, R., López-Jurado, J., Alemany, F., 2012. Geographically and environmentally driven spawning distributions of tuna 
species in the western Mediterranean Sea. Marine Ecology Progress Series 463, $273-$ 284. doi:10.3354/meps09800

Rodhouse, P.G., Nigmatullin, C.M., 1996. Role as consumers. The Role of Cephalopods in the World's Oceans. Philosophical Transactions of the Royal Society of London. Series B. 351, 1003-1022.

Rodhouse, P.G.K., Pierce, G.J., Nichols, O.C., Sauer, W.H.H., Arkhipkin, A.I., Laptikhovsky, V. V., Lipiński, M.R., Ramos, J.E., Gras, M., Kidokoro, H., Sadayasu, K., Pereira, J., Lefkaditou, E., Pita, C., Gasalla, M., Haimovici, M., Sakai, M., Downey, N., 2014. Advances in Cephalopod Science: Biology, Ecology, Cultivation and Fisheries, in: Vidal, E. (Ed.), Advances in Marine Biology, Advances in Marine Biology. Academic Press, pp. 99-233. doi:10.1016/B978-0-12-800287-2.00002-0

Roper, C.F.E., Nigmatullin, C., Jereb, P., 2010. Family Ommastrephidae, in: Jereb, P., Roper, C.F.E. (Eds.), Cephalopods of the World. An Annotated and Illustrated Catalogue of Species Known to Date. Volume 2. Myopsid and Oegopsid Squids. FAO Species Catalogue for Fishery Purposes. No. 4, Rome, p. 269-347.

Rossi, V., Ser-giacomi, E., López, C., Hernández-garcía, E., 2014. Hydrodynamic provinces and oceanic connectivity from a transport network help designing marine reserves. Geophysical Research Letters 2883-2891. doi:10.1002/2014GL059540.Received

Roura, Á., González, Á.F., Pascual, S., Guerra, Á., 2010. A molecular approach to identifying the prey of cephalopod paralarvae. ICES Journal of Marine Science 67, 1408-1412.

Sartor, P., Belcari, P., Carboell, a., Gonzalez, M., Quetglas, a., Sánchez, P., 1998. The importance of cephalopods to trawl fisheries in the western Mediterranean. South African Journal of Marine Science 20, 67-72. doi:10.2989/025776198784126313

Saville, A., 1977. Survey methods of appraising fishery resources. Food and Agriculture Organization of the United Nations $76 \mathrm{pp}$.

Schindler, D.E., Hilborn, R., Chasco, B., Boatright, C.P., Quinn, T.P., Rogers, L.A., Webster, M.S., 2010. Population diversity and the portfolio effect in an exploited species. Nature 465, 609-12. doi:10.1038/nature09060

Segawa, S., Nomoto, A., 2002. Laboratory growth, feeding, oxygen consumption and ammonia excretion of Octopus ocellatus. Bulletin of Marine Science 71, 801-813.

Semmens, J.M., Pecl, G.T., Villanueva, R., Jouffre, D., Sobrino, I., Wood, J.B., Rigby, P.R., 2004. Understanding octopus growth: patterns, variability and physiology. Marine and Freshwater Research 55, 367-377. doi:10.1071/MF03155

Souplet, A., 1996. Définition des estimateurs, in: Bertrand, J.A. (Ed.), Campagne Internationale de Chalutage Démersal En Méditerranée (Medits 95). p. Etude 94/047 IFREMER/CE, 94/011 IEO/CE, 94/057 SIB.

Vasilakopoulos, P., Maravelias, C.D., Tserpes, G., 2014. The alarming decline of Mediterranean fish stocks. Current Biology 24, 1643-8. doi:10.1016/j.cub.2014.05.070

Vecchione, M., Allcock, L., Piatkowski, U., Jorgensen, E., Barratt, I., 2009. Persistent Elevated Abundance of Octopods in an Overfished Antarctic Area. Smithsonian at the Poles: Contributions to International Polar Year Science 197-203.

Woillez, M., Poulard, J., Rivoirard, J., Petitgas, P., Bez, N., 2007. Indices for capturing spatial patterns and their evolution in time, with application to European hake (Merluccius merluccius) in the Bay of Biscay. Ices Journal of Marine Science 64, 
$537-550$.

Zuur, A.F., Pierce, G.J., 2004. Common trends in northeast Atlantic squid time series.

Journal of Sea Research 52, 57-72.

Zuur, A.F., Tuck, I.D., Bailey, N., 2003. Dynamic factor analysis to estimate common trends in fisheries time series. Fisheries Research 552, 542-552. doi:10.1139/F03-030

\section{APPENDIX}

Table A1: DFA results for Octopus vulgaris and Illex coindetii from the eastern and the western Mediterranean basin. Shown are the twelve best models for each case (best model in bold). For each model, the model number, the error matrix structure (R), the number of common trends (m), and the corrected AIC (AICc) are given.

\begin{tabular}{|l|l|r|r|r|l|}
\hline $\begin{array}{l}\text { Octopus eastern } \\
\text { Mediterranean }\end{array}$ & & & & & \\
\hline MODEL & R & $\mathrm{m}$ & \multicolumn{1}{|l|}{ logLik } & $\mathrm{K}$ & \multicolumn{1}{l|}{ AICc } \\
\hline $\mathbf{1}$ & diagonal and equal & $\mathbf{1}$ & $-\mathbf{1 2 6 . 1 4}$ & $\mathbf{7}$ & $\mathbf{2 6 7 . 5 6}$ \\
\hline $\mathbf{7}$ & equalvarcov & 1 & -126.11 & 8 & 269.89 \\
\hline 4 & diagonal and unequal & 1 & -123.80 & 12 & 275.40 \\
\hline 2 & diagonal and equal & 2 & -125.89 & 12 & 279.59 \\
\hline 8 & equalvarcov & 2 & -125.77 & 13 & 282.03 \\
\hline 5 & diagonal and unequal & 2 & -123.38 & 17 & 288.72 \\
\hline 3 & diagonal and equal & 3 & -125.89 & 16 & 290.76 \\
\hline 9 & equalvarcov & 3 & -125.77 & 17 & 293.49 \\
\hline 6 & diagonal and unequal & 3 & -123.39 & 21 & 301.44 \\
\hline 10 & unconstrained & 1 & -115.34 & 27 & 307.26 \\
\hline 11 & unconstrained & 2 & -119.70 & 32 & 337.45 \\
\hline 12 & unconstrained & 3 & -120.26 & 36 & 358.44 \\
\hline & & & & & \\
\hline
\end{tabular}

\begin{tabular}{|c|c|c|c|c|c|}
\hline $\begin{array}{l}\text { Octopus western } \\
\text { Mediterranean }\end{array}$ & & & & & \\
\hline MODEL & $\mathrm{R}$ & $\mathrm{m}$ & logLik & $\mathrm{K}$ & $\mathrm{AICC}$ \\
\hline 7 & equalvarcov & 1 & -225.86 & 11 & 475.39 \\
\hline 1 & diagonal and equal & 1 & -227.79 & 10 & 476.96 \\
\hline 8 & equalvarcov & 2 & -218.03 & 19 & 479.15 \\
\hline$>$ & diagonal and equal & 2 & -221.54 & 18 & 483.64 \\
\hline 4 & diagonal and unequal & 1 & -224.87 & 18 & 490.29 \\
\hline 9 & equalvarcov & 3 & -215.18 & 26 & 492.26 \\
\hline 3 & diagonal and equal & 3 & -217.81 & 25 & 494.72 \\
\hline 5 & diagonal and unequal & 2 & -216.85 & 26 & 495.58 \\
\hline 6 & diagonal and unequal & 3 & -213.35 & 33 & 509.32 \\
\hline 10 & unconstrained & 1 & -190.14 & 54 & 540.39 \\
\hline 11 & unconstrained & 2 & -180.19 & 62 & 558.08 \\
\hline 12 & unconstrained & 3 & -178.54 & 69 & 592.66 \\
\hline
\end{tabular}


ACCEPTED MANUSCRIPT

\begin{tabular}{|c|c|c|c|c|c|}
\hline $\begin{array}{l}\text { Illex eastern } \\
\text { Mediterranean }\end{array}$ & & & & & \\
\hline MODEL & $\mathrm{R}$ & $\mathrm{m}$ & logLik & $\mathrm{K}$ & $\mathrm{AlCc}$ \\
\hline 7 & equalvarcov & 1 & -125.94 & 8.00 & 269.52 \\
\hline 1 & diagonal and equal & 1 & -127.38 & 7.00 & 270.01 \\
\hline 4 & diagonal and unequal & 1 & -124.70 & 12.00 & 277.11 \\
\hline 8 & equalvarcov & 2 & -124.55 & 13.00 & 279.49 \\
\hline 2 & diagonal and equal & 2 & -126.16 & 12.00 & 280.03 \\
\hline 5 & diagonal and unequal & 2 & -120.96 & 17.00 & 283.67 \\
\hline 9 & equalvarcov & 3 & -124.55 & 17.00 & 290.85 \\
\hline 3 & diagonal and equal & 3 & -126.94 & 16.00 & 292.69 \\
\hline 6 & diagonal and unequal & 3 & -120.65 & 21.00 & 295.62 \\
\hline 10 & unconstrained & 1 & -111.45 & 27.00 & 298.81 \\
\hline 11 & unconstrained & 2 & -110.28 & 32.00 & 317.56 \\
\hline 12 & unconstrained & 3 & -112.23 & 36.00 & 340.87 \\
\hline
\end{tabular}

\begin{tabular}{|c|c|c|c|c|c|}
\hline $\begin{array}{l}\text { Illex western } \\
\text { Mediterranean }\end{array}$ & & & & & \\
\hline MODEL & $\mathrm{R}$ & $\mathrm{m}$ & logLik & $\mathrm{K}$ & $\mathrm{AlCc}$ \\
\hline 1 & diagonal and equal & 1 & -219.27 & 10.00 & 459.95 \\
\hline 7 & equalvarcov & 1 & -219.22 & 11.00 & 462.13 \\
\hline 4 & diagonal and unequal & 1 & -213.34 & 18.00 & 467.26 \\
\hline 2 & diagonal and equal & 2 & -217.28 & 18.00 & 475.16 \\
\hline 8 & equalvarcov & 2 & -217.07 & 19.00 & 477.27 \\
\hline 5 & diagonal and unequal & 2 & -212.36 & 26.00 & 486.67 \\
\hline 3 & diagonal and equal & 3 & -216.77 & 25.00 & 492.69 \\
\hline 9 & equalvarcov & 3 & -216.72 & 26.00 & 495.40 \\
\hline 6 & diagonal and unequal & 3 & -210.96 & 33.00 & 504.66 \\
\hline 10 & unconstrained & 1 & -193.79 & 54.00 & 548.14 \\
\hline 11 & unconstrained & 2 & -190.95 & 62.00 & 580.30 \\
\hline 12 & unconstrained & 3 & -188.71 & 69.00 & 613.99 \\
\hline
\end{tabular}




\section{Octopus vulaaris}
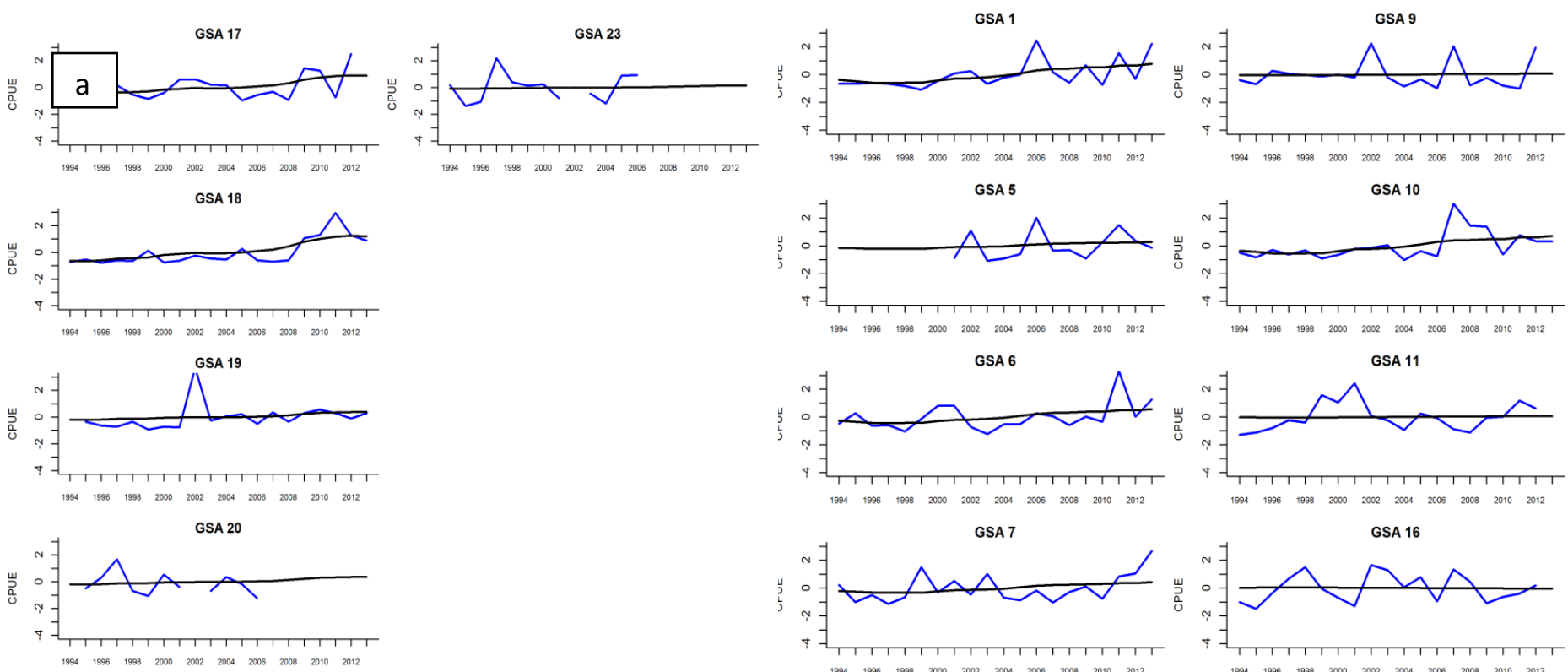

GSA 7

GSA 16
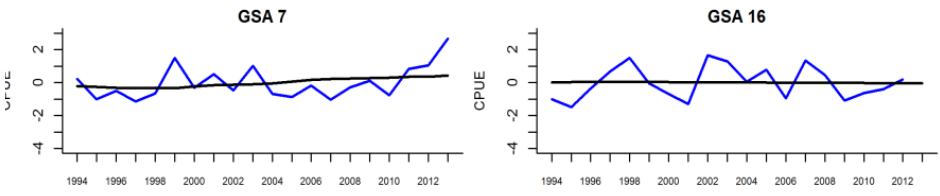

GSA 22
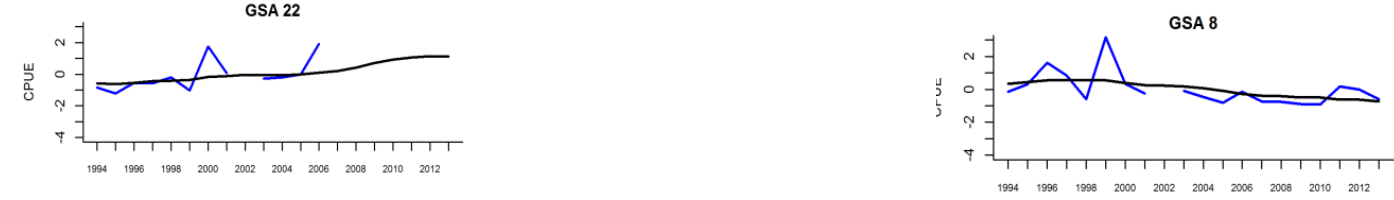

Western basin

Eastern basin

\section{Illex coindetii}

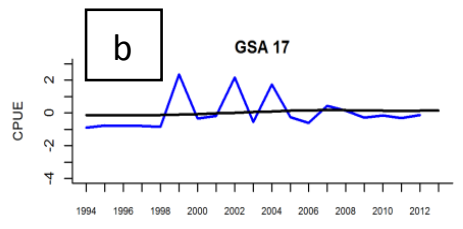

GSA 18
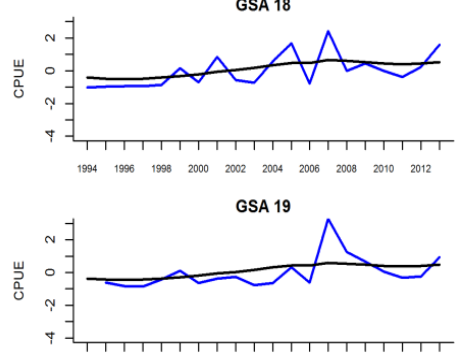

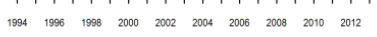

GSA 20

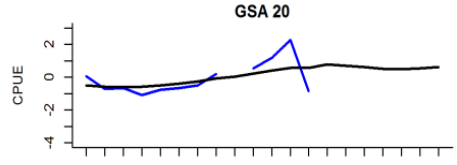

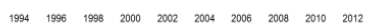

GSA 22

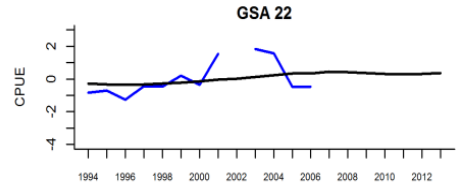

Eastern basin
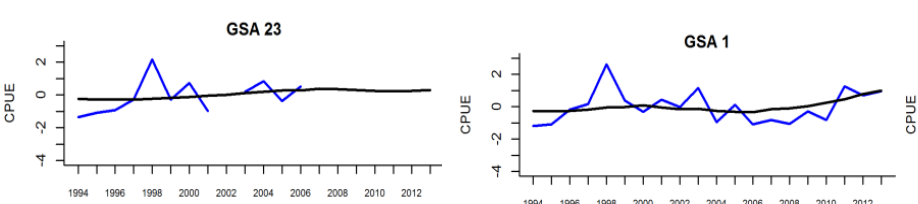

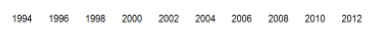

GSA 5
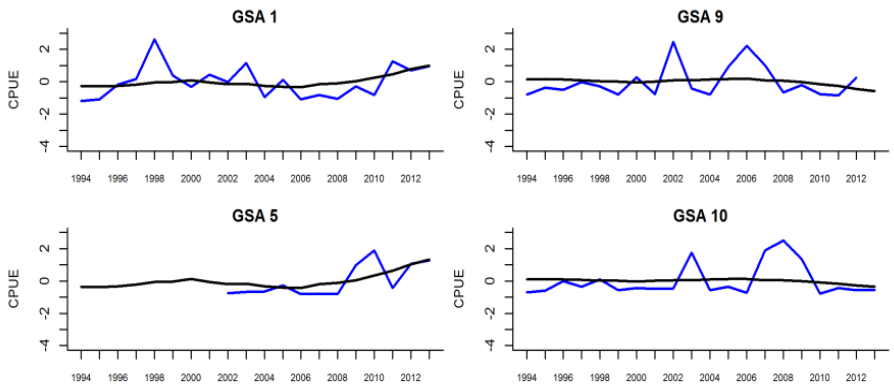

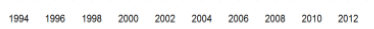
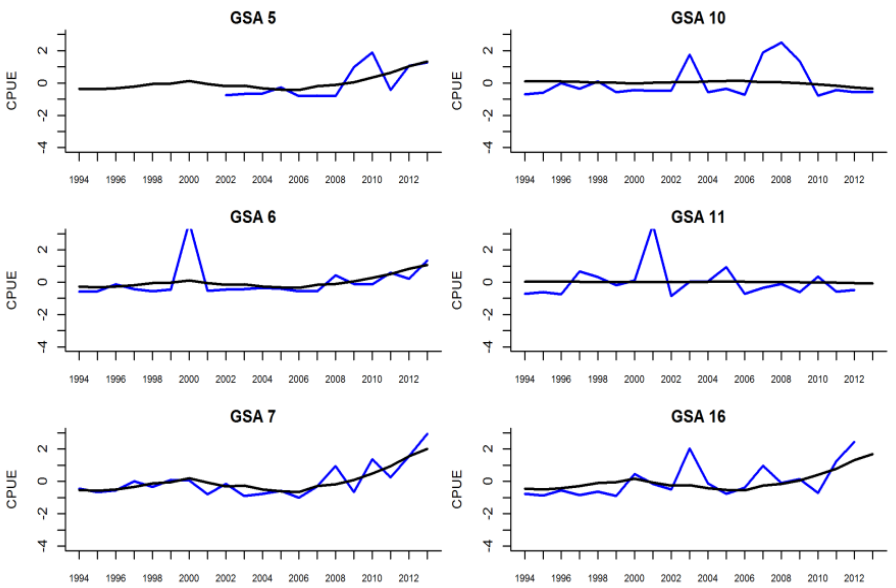

GSA 8

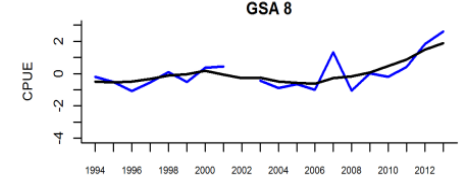

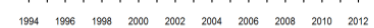

Western basin 
Figure A1: Model fits (blue lines) of the best models obtained by DFA on standardized CPUE time series for a) Octopus vulgaris and b) Illex coindetii; GSAs are separated into eastern (left) and western (right) basin. 